\title{
Great recession or great transformation of the XXI
}

\section{century}

\section{Introduction}

We are currently facing a financial crisis of magnitudes never before seen, ${ }^{1,2}$ also there is an economic crisis in branches as important as automotive ${ }^{3}$ and energy. ${ }^{4}$ We are facing a food crisis and a deep ecological crisis. ${ }^{5,6}$ If we add to those economic crises those of political nature, such as the loss of legitimacy and effectiveness of the institutions of representative democracy and the erosion of the maneuvering capacity of national states, ${ }^{7}$ we can conclude that in reality all these crises are interrelated and form a vicious circle. Besides, the resurgence of racism and several forms of violent intolerance are making the things worse.

Due to the historical conditions present in the world, we can think that in fact it is not a crisis like so many others previously occurred, but that we are facing a great transformation of the entire Western civilization based on the industrialization and commodification of all activities of human beings, possible due to the use and abuse of fossil fuels and in general of the planet's resources. ${ }^{8,9}$ This limit situation will probably lead to a change in civilization, not necessarily better than the current one, but without doubt different. It is possible that the next 50 or maybe more years will be similar to the years of confusion, violence and disorganization that followed the fall of the Roman Empire in Europe, until feudalism introduced a new order. We do not know if it will be a "neo-feudalism" and if it could bring the solution to the long period of transition and chaos in which we are already entering, but we can be sure that the world we know is announcing its demise, which is being caused by the irresponsible, selfish and ambitious actions of the humankind.

Hardly anyone can doubt that today we are immersed in, at least, a crisis, and probably in more than one of them. The opinions diverge in the enumeration, prioritization and above all, the theoretical understanding of the current crisis. The idea that I would like to propose is based mainly on the approaches of two authors: Immanuel Wallerstein ${ }^{10-12}$ and Karl Polanyi. ${ }^{13}$ Although I also borrow statements from many other contemporary scholars, I try to frame them in the great theories of the first two authors. From Wallerstein I take his conceptualization of the Long Waves of Kondratieff, and from Polanyi I borrow the approach of the great transformation based on a double movement that I will explain later. Let's first see the position of Wallerstein, who in addition to his great works of long breath, regularly publishes his comments on the economic and political events underway. In numerous texts Wallerstein has explained his interpretation of the idea of Long Waves, originally formulated by Kondratieff. The essential message consists of the presence of cycles of 50 to 60 years of duration, according to variables such as production, investments, benefits and others associated with them.

Long waves are divided into two phases. Phase A is expansive and phase B is contractive. Statistically these waves can be verified throughout the history of capitalism, particularly since the European Industrial Revolution. For our purposes, it should be noted that the last phase A began in 1945 and continued until the mid-1970s. Then phase $\mathrm{B}$ began, in which we still find ourselves. A comparison with previous historical experiences indicates that the characteristic of phases B is
Volume 2 Issue 3 - 2018

\author{
Carlos J Maya Ambía \\ Department of Social Sciences and Humanities, Universidad de \\ Guadalajara, México
}

Correspondence: Carlos J Maya Ambía, Department of Social Sciences and Humanities, Universidad de Guadalajara, Prol. Parres Arias I50, Los Belenes, Zapopan, Jalisco, C.P. 45I32, Mexico, Tel 5233-12485225,

Email carlosmayaambia@hotmail.com

Received: May 21, 2018| Published: June 06, 2018

a decrease in the profit rates derived from productive activities and in general a slowdown in the process of capital accumulation. Phases B took place, for example, from 1873 to 1893 , when free competition capitalism experienced a long depression; and, between 1914 and 1940, a time characterized by a decline of capitalism, imperialist wars, revolutions and counterrevolutions. This last phase B leads to a great war and also to the establishment of a new international order, both economically and politically. In this last area perhaps the most relevant has been the change of world hegemony, namely, the end of Pax Britannica and its replacement by the Pax Americana. This fact indicates that we must also take into account what Wallerstein calls hegemonic cycles and that they have a different length from that of long waves, but are closely linked with them.

If we compare the previous phase $\mathrm{B}$ with the current one, we can observe that in both cases there were strong responses to the decreases in the rate of profit of the invested capital. In economic terms, the most notable phenomenon was the intensification of the flows of goods, capital and people on international scale. Because of this reason many authors speak of globalization during the inter-war period, of comparable levels and in some aspects even superior to the current neoliberal globalization. The dynamics of that phase B led to the Crisis of 1929-33, which was responsible for making the necessary corrections. Here we must remember that crisis means catharsis, that is, a strong purge, a thorough cleansing, where necessarily there are many losers and some winners. The most important winners were the companies that as transnational enterprises would dominate the panorama in the second half of the $20^{\text {th }}$ century. The losers in that crisis went bankrupt and disappeared. The winners promoted changes that transformed the economic world. In the international economy the creation of the system born in Bretton-Woods was the most relevant and its central point was the US dollar as a world currency. In the current phase B the most notorious has been neoliberal globalization as a response to the crisis of the previous paradigm of Keynesian orientation and in general focused on a deep and broad state intervention in the economy. This also explains why this phase B has been so prolonged compared to previous ones. In other words, the activities of organizations such as the US Department of the Treasury and the Federal Reserve, the IMF, the governments of the countries of Western Europe and Japan are responsible for the long duration of this phase B. 
There are similarities between all phases B, for example, when the rate of profit derived from productive activities decreases, capital flows towards speculative activities. As wage costs rise in more developed centers, production shifts to locations characterized by abundant and cheap labor. When there is a relative oversupply, new markets are sought. However, it should be emphasized that it is not a cyclicity in which everything starts again under the same conditions. On the contrary, as Ernest Mandel emphasized almost 30 years ago, and has repeated several times, each phase of the Kondratieff waves has its own historical identity. In other words, they develop in time and the arrow of time knows only one direction, it is irreversible. ${ }^{14}$

The historical context of the current phase B of the long wave started in 1945 and it should end at the beginning of the 21 st century. This phase is marked by some factors that are presented for the first time in the history of humanity and some others that are not totally new but now assume dimensions never before thought. Among the latter we can mention the food crisis and the phenomenon of poverty. It is not the first time that large human groups are hungry and poor. The tragedy now is that even if there are the means for these millions of people to overcome their current conditions, each day the possibility that they do so is further away. Nor this is the first financial crisis, although connoisseurs think it will be much worse than the 1929-33 crises. This is surely due to the fact that the economies and financial systems of the countries of the planet have never been so closely linked before. Nor is it the first time that an economic paradigm shows its exhaustion. So did the mercantilist, the liberal-Manchesterian, the Keynesian, the developmentalist of ECLAC, the Marxist in its Soviet version, and now the neoliberal model. What is dramatic is that there does not seem to be an alternative paradigm in view that is presented as a viable candidate to build a new economy.

On the other hand, completely new in history are the energy crisis and the environmental crisis. Not only capitalism, but all modern civilization is based on the use of fossil fuels. The new thing is that it has reached a limit situation. It is not possible to continue with the rhythm of use (and abuse) of non-renewable energies and it is also not possible that the vast majority of the world population will one day have access to the current levels of energy consumption characteristic of advanced countries. The search for alternative energies, such as nuclear, solar, wind, and others is an indication of the seriousness of the prevailing situation. Closely linked to the energy crisis we are experiencing the environmental crisis, whose most worrying aspect, but not the only one, is global warming. In fact, the industrialization of agriculture and the openly depredatory approach of most human activities related to nature have led to a unique moment due to its seriousness in history. What is in danger is not only capitalism or industrial civilization, but life itself on the planet. Some people deny the danger; others minimize it or recognize it but believe that there are ways to overcome it. But there are also those who think, like me, that humanity has learned nothing from its history and not only commits the same mistakes as its ancestors, but now commits them on a larger scale because it has greater technical resources to do damage deeper and more durable to the entire planet.

In Wallerstein's opinion the current world-system is entering a phase of highly chaotic turbulence that can last between 20 and 50 years. In this period of turbulence, which could find a certain historical parallel with the situation in Europe at the fall of the Roman Empire, something worse could appear than current capitalism, that is, something more polarized and hierarchical, a world divided by walls, not just material, buy ideological and moral ones; or something better, relatively democratic and egalitarian, a world of tolerance and respect to different social values. The outcome will not depend on economic factors, but on the construction of consensus and a political will with an alternative project. At this point we can include Polanyi to complement Wallerstein's reflections. According to this author in the history of capitalism there have been alternating two fundamental movements. One is the self-expanding movement of the market and the other one is the self-protective movement of society. The first is guided by the logic of profit and therefore turns everything into a commodity, especially three "objects" that cannot really become merchandise, so it calls them "quasi-commodities". They are land, money and the work force. Polanyi's explanation is very clear. Merchandise is that which human beings expressly produce for sale in the market, with the expectation of obtaining a profit from this operation. Obviously the earth, that is, the planet and everything it contains (land, water, minerals, etc.) was not created by human beings and was already there when man appeared on the face of the Earth. Money is not a commodity either, but rather the creation, more or less arbitrarily and through force, of a legal instrument by a political institution. The labor force, on the other hand, is a euphemism to refer to the human beings who find it necessary to sell it in order to survive. It is clear that human beings are not created to be sold in any market and if they ever were, this was limited to slaves.

In its self-expansive movement, then, the market tries to convert everything that finds on its way into a commodity and convert market relations into the paradigm of all relationships between human beings. This operation can be profitable for some time, but sooner or later it endangers the system itself and in the first place damages society, which seeks to protect itself against the supposedly selfregulated and self-regulating market. At this time society makes use of its institutions, the state in the first place, to put order in economic activities and subordinate particular economic interests to general social interests. According to this pattern, the alternation of economic paradigms can be interpreted, giving priority to the market and others to the state. As neoliberalism has given priority to the market, it is to be expected that the next, whatever it may be called, will give priority to the state or some form of political regulation that complies with the current functions of the national states.

This logic exposed by Polanyi is confirmed when Wallerstein argues that in the short term we are moving towards a world characterized by the following four elements:

a. Protectionism

b. Greater direct involvement of governments in production.

c. Populist governments oriented towards the redistribution of wealth, which may be social-democratic or right-wing authoritarian.

d. Exacerbation of social conflicts within states, which may be of an ethnic, religious, generational, etc. type.

Most likely, these elements combine to overcome the minimum point reached by Kondratieff's current phase B, but what is crucial is that the new, expansive phase A will occur within a civilization frame qualitatively different from the current one, whose signs of extinction have become unavoidable. That is to say, we are not only facing several simultaneous crisis (economical, financial, ecological and food crisis) but we are confronting a crisis of civilization, the crisis of the modern industrial civilization. There is no point in talking 
about the fact that we are heading towards a post-industrial or postmodern civilization, because what comes next is not clear or definite. Concepts such as post-modernity, knowledge or information society actually refer to ideal constructions that continue to move within the same framework of civilization based on ultra-industrialization based on the consumption of fossil fuels. What we face is something more profound, it is a new civilization that will not necessarily be better than the current one and its conformation does not depend just on economic trends, but on conceptions of the world, of life, of the role of human beings in the universe, of the relations between humans, between the sexes, between generations, between living beings, between the past, the present and the future.

The seriousness of the current situation is that we have thousands of gigabytes of information and knowledge, but very little wisdom, which timidly appears from time to time. Therefore the current humanity seems to be a giant encased in a powerful armor, which advances imprudently towards the abyss with his eyes blocked by the heavy visor of his helmet that prevents him from seeing his reality. All these facts and trends lead me to think that we are not only facing a deep recession that concerns the economy, but in front of a new great transformation, such as the one studied by Karl Polanyi and which referred to the creation of an entire civilization based on the centrality of the market and the predominance of industry. I envisage a new great transformation in the medium and long term for three main reasons, although perhaps they are not the only ones:

a. Industrialization has reached its limit due to the imminent depletion of fossil fuels:

b. There is no candidate to fill the vacuum that is creating the decline of US hegemony. Rather, many forces are emerging, some of them socially disintegrating.

c. Exhaustion of the anthropocentric paradigm and need to recognize the danger faced by life on the planet and not only human life, due to the systematic and large-scale depredation carried out by humans to the detriment of the Earth.

Finally, it is not clear the direction that this great transformation will take.

Broadly speaking one can think of two possibilities.

One is the chaotic, centrifugal and asymmetric alternative, where the common denominator of all societies that survive will be precariousness in all its aspects and perhaps some islets of relative wealth or well-being. Something similar to the centuries of darkness, chaos, vandalism and violence that took place in Europe at the fall of the Roman Empire and that came to find its solution in the creation of feudalism. If so, a "neofeudalism" could be what appears in the future. The other alternative, less probable, but more desirable, would be the construction of medium and small scale societies, based on economy not driven by profit, but by austerity, self-sufficiency and zero growth. I therefore discard paradisiacal scenarios or reissues of utopian projects such as a new socialism and the like. Of course I am aware that the future will probably be different to all our projections, but even if it is, it is useful to build some of them, so as not to continue running blindly, as we are doing now, towards our own destruction.

\section{Acknowledgments}

None.

\section{Conflict of interest}

The author declares that there is no conflict of interest.

\section{References}

1. Crotty J. Structural causes of the global financial crisis: a critical assessment of the new financial architecture. Cambridge Journal of Economics. 2009;33(4):563-580.

2. Foster JB, Magdoff F. The great financial crisis: causes and consequences. New York: Monthly Review Press; 2009. 144 p.

3. Sturgeon T, Van Biesebroeck J. Effects of the Crisis on the Automotive Industry in Developing Countries: A Global Value Chain Perspective. Newyork: World Bank Policy Research Working Paper No 5330; 2010. $31 \mathrm{p}$.

4. Newton DE. World energy crisis: a reference handbook. Santa Barbara: ABC-CLIO; 2012. 334 p.

5. Clapp J. The Global Food Crisis: Governance Challenges and Opportunities. Cohen MJ, editor. Ontario: Wilfrid Laurier University Press; 2009. 288 p.

6. Immanuel Wallerstein. Review (Fernand Braudel Center): Food, Energy, Environment: Crisis of the Modern World-System. Research Foundation of State University of New York. 2010;33(2):287-293.

7. Mair P. Ruling the Void: The Hollowing of Western Democracy. London: Verso Books; 2013. $160 \mathrm{p}$

8. Altvater E. Das Ende des Kapitalismus, wie wir ihn kennen. 7th ed. Münster: Verlag Westfälisches Dampfboot; 2011.

9. Moore JW. Anthropocene or Capitalocene? Nature, History, and the Crisis of Capitalism. Oakland: PM Press; 2016. 240 p.

10. Wallerstein I. Review (Fernand Braudel Center): Long Waves in History. Spring. 1984;7(4):559-575.

11. Wallerstein I. After Liberalism. New York: New Press; 1995. 288 p.

12. Wallesrtein I. World-Systems Analysis. An Introduction. Durham: Duke University Press; 2004. 109 p.

13. Polanyi K. The Great Transformation. The Political and Economic Origins of Our Time. Boston: Beacon Press; 2001.360 p.

14. Kleinknecht A, Mandel E. New Findings in Long-Wave Research. Wallerstein I, editor. New York: St. Martin's Press; 1992. 348 p. 